\title{
Current status of infrapopliteal artery stenting in patients with critical limb ischemia
}

\author{
Estado atual do uso de stents na artéria infrapolitea em pacientes \\ com isquemia crítica do membro
}

Marc Bosiers, ${ }^{1}$ Koen Deloose, ${ }^{1}$ Rodrigo Moreialvar, ${ }^{2}$ Jurgen Verbist, ${ }^{3}$ Patrick Peeters ${ }^{3}$

\begin{abstract}
Due to the fear that early thrombosis and late luminal loss resulting from intimal hyperplasia might impede sustained patency of small-caliber arteries, such as those of the infrapopliteal bed, stent implantation in below-knee vessels remains controversial and is generally reserved for cases with a suboptimal outcome after percutaneous transluminal angioplasty (i.e. $>50 \%$ residual stenosis, flow-limiting dissection). Although evidence starts to build, favoring the use of stenting in the tibial area, results of well-conducted randomized controlled trials have to be awaited to change this strategy. Because of diameter similarities with coronary arteries, the first stents applied in the infrapopliteal vessels were all coronary devices. Once the feasibility of the stenting approach with these coronary products was shown, device manufacturers started to develop a dedicated infrapopliteal product range. To date, a broad spectrum of stent types has been used and investigated for the given indication. This article overviews the available literature and results of different balloon-expandable (bare metal, passive coated, drug eluting), self-expanding and absorbable stent types available for below-the-knee application and gives recommendations for future device technology advancements.
\end{abstract}

Keywords: Stents, ischemia, arteriosclerosis.

\section{Introduction}

Critical limb ischemia (CLI) is an end-stage manifestation of peripheral artery disease (PAD) and typically describes patients with ischemic rest pain (Rutherford category 4), or patients with ischemic skin lesions, either ulcers or gangrene (Rutherford category 5-6). ${ }^{1}$

CLI may cause, or contribute to, significant chronic pain, local and systemic sepsis, tissue loss, other local and systemic complications, eventual amputation or even

\section{Resumo}

Devido ao receio de que a trombose precoce ou a estenose tardia por hiperplasia intimal possam impedir a manutenção da perviedade em vasos de pequeno calibre, o uso de stents pós-angioplastia no leito arterial infrapoplíteo permanece controverso e geralmente é reservado aos casos de resultado subótimo após angioplastia transluminal percutânea (isto é, estenose residual $>50 \%$ ou dissecção com limitação do fluxo). Apesar de evidências começarem a favorecer o uso de stents no segmento tibial, é necessário aguardar o resultado de ensaios controlados, randomizados e bem conduzidos para mudar esta estratégia. Sendo estes vasos infrapoplíteos de diâmetro similar às artérias coronárias, os primeiros stents usados neste segmento eram todos stents coronários. Uma vez que se mostrou exeqüível o uso destes stents, a indústria iniciou o desenvolvimento de uma linha de produtos específicos ao segmento infrapoplíteo. Atualmente uma gama de stents tem sido usada e investigada para este fim. Este artigo revê resultados disponíveis na literatura com diferentes stents expansíveis por balão (metal não-recoberto, revestimento passivo, eluição de fármacos), auto-expansíveis e absorvíveis disponíveis para o segmento infrapoplíteo e apresenta recomendações para os futuros avanços tecnológicos dos dispositivos.

Palavras-chave: Stents, isquemia, arteriosclerose.

death. Complication management of untreated CLI consumes a significant amount of healthcare resources. Amputation remains a common procedure and is likely to be higher due to an aging population, increasing recognition of CLI in the aged and a recognized trend towards a higher occurrence of diabetes. Patients requiring major amputation face a diminished quality of life, an unfavorable natural history and need extensive resources for their post-amputation rehabilitation and course. Such resources would be better deployed in an

1. Department of Vascular Surgery, AZ St. Blasius, Dendermonde, Belgium.

2. Department of Angiology and Vascular Surgery, Hospital das Clínicas, Universidade Federal de Minas Gerais (UFMG), Belo Horizonte, MG, Brazil.

3. Department of Cardiovascular and Thoracic Surgery, Imelda Hospital, Bonheiden, Belgium.

No conflicts of interest declared concerning the publication of this article.

Manuscript received Feb 21 2008, accepted for publication Jul 092008.

J Vasc Bras. 2008;7(3):248-255.

Copyright $\odot 2008$ by Sociedade Brasileira de Angiologia e de Cirurgia Vascular 
aggressive approach to save affected limbs in those suffering from CLI early after identification of pathology in order to prevent progression to more serious complications.

Distal bypass for limb salvage with autogenous conduit is an excellent option for patients who are good candidates for surgical revascularization. However, prohibitive comorbidities, inadequate conduit, and lack of suitable distal targets for revascularization all conspire to erode the pool of good surgical bypass candidates significantly. Moreover, with the advent of feasible techniques for endovascular therapy for below-knee (BK) lesions causing CLI, there is a need to reevaluate current reporting standards for lower extremity revascularization. Morbidity following infrageniculate bypass surgery (IBS) is relatively underweighted in our present strategy of assessing post-bypass surgery outcomes. Markers of perioperative morbidity such as index limb reoperation in 3 months, hospital readmission following IBS, or wound healing time exceeding 3 months have all been reported to run in the 50\% range and are examples of factors which may favor endovascular therapeutic strategies.

Thus, although surgery remains a good option for some patients with CLI, endovascular therapy offers the advantages of local anesthesia and potentially reduced costs (even anticipating the need for reintervention in many patients) and shorter hospital stays when compared with IBS. ${ }^{2-5}$ The bypass vs. angioplasty in severe ischemia of the leg (BASIL) trial participants concluded based on the results of their randomized controlled trial (RCT) comparing PTA vs. bypass surgery in CLI-patients after 1 year that PTA is cheaper as firstline treatment and that both interventions have similar outcomes in terms of amputation-free survival. ${ }^{6}$ Although the BASIL trial is the first to validate, based on level-1 evidence, the endovascular treatment strategies as an acceptable option for CLI-patients, it should be remembered that the number of patients eligible for randomization only represented $30 \%$ of those with CLI and $2 \%$ of those with PAD. ${ }^{7}$ This resulted in an important selection bias for the trial and potentially precludes the application of the BASIL trial results to the general population. More importantly, the recently renewed
Trans-Atlantic Inter-Society Consensus Document on Management of PAD (TASC II) indicates there is increasing evidence to support a recommendation for angioplasty in patients with CLI and BK artery occlusion where in-line flow to the foot can be reestablished and where there is medical comorbidity. Furthermore, they summarize that in the case of infrapopliteal percutaneous transluminal angioplasty (PTA), technical success may approach $90 \%$ with resultant clinical success of approximately $70 \%$ in some series of patients with CLI. Salvage rates are reported as being slightly higher. ${ }^{1}$

The treatment strategy for BK lesions in CLIpatients is rapidly evolving, but although the use of stents is common in other peripheral vessels, their application in the infrapopliteal bed remains controversial. The fear that early thrombosis and late luminal loss due to intimal hyperplasia formation potentially leads to insufficient long-term patency rates can explain the reluctance of implanting stents in these small-diameter vessels. Therefore, infrapopliteal stent implantation is generally reserved for cases with a suboptimal outcome after PTA (i.e. $>50 \%$ residual stenosis, flow-limiting dissection).

Only recently has evidence started to be built, favoring use of stents in the tibial area. Because of diameter similarities with coronary arteries, the first stents applied in the infrapopliteal vessels were all coronary devices. Once the feasibility of the stenting approach with these coronary products was shown, device manufacturers started to develop a dedicated infrapopliteal product range (Figure 1).

\section{Bare metal balloon expandable stents}

The Multilink Vision (Abbott Vascular, Redwood City, CA, USA) is a premounted bare metal balloonexpandable stent L-605 Cobalt Chromium alloy (CoCr) coronary stent with radial strength and fluoroscopic visibility superior to stainless steel stents. A recent publication described our experience with this type of stent in a cohort of 50 patients with CLI who were all diagnosed with infragenicular occlusive arterial disease. After 1 year a limb salvage rate of $89.3 \%$ was calculated with a duplex derived primary patency of the treated vessel of only $62.8 \% .^{8}$ Other studies using bare metal stents (BMS) supported our findings. Scheinert et al. found a 


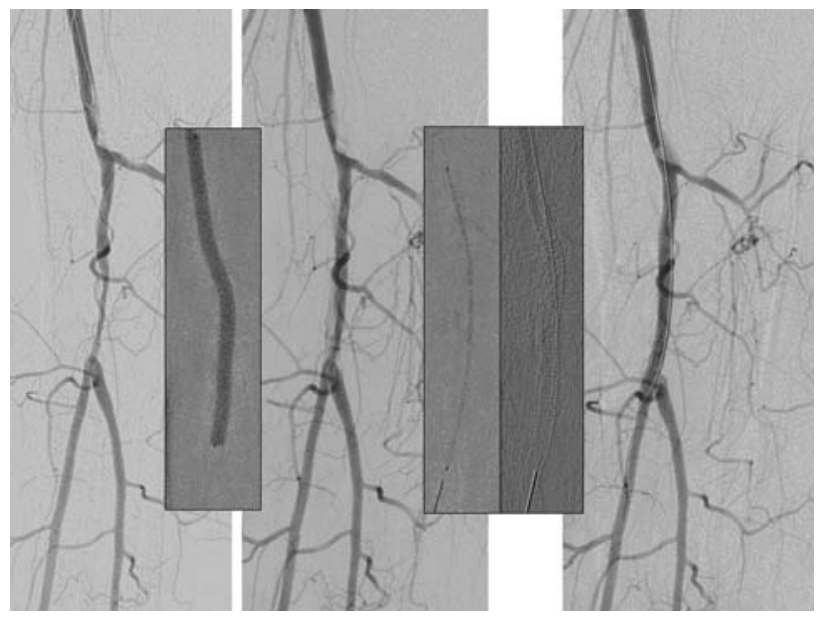

Figure 1 - Stenting currently remains reserved for suboptimal percutaneous transluminal angioplasty: A) preoperative angiographic imaging shows lesion at the level of the tibiofibular trunk, which is B) suboptimally treated with percutaneous transluminal angioplasty followed by C) successful stenting with Chromis Deep (Invatec, Roncadelle, Italy)
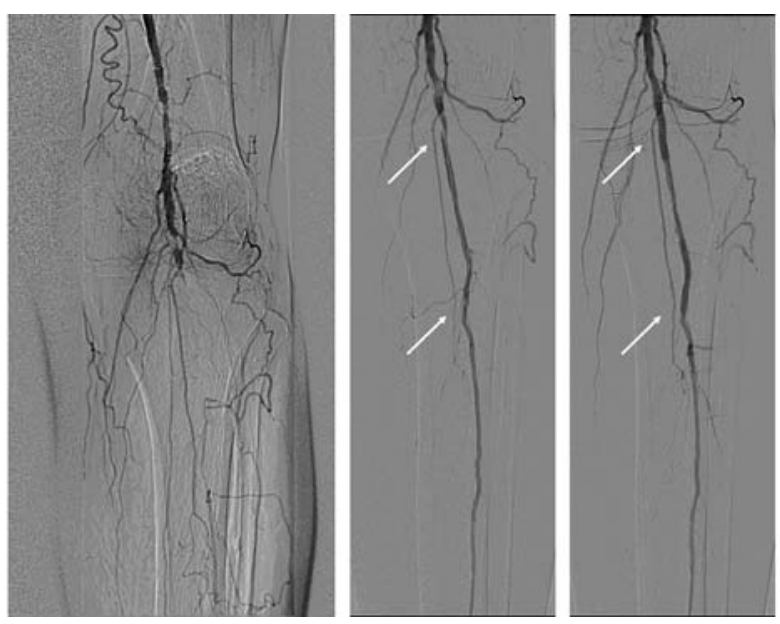

Figure 2 - A) Preoperative angiographic imaging showing total occlusion of the infragenicular vascular bed treated by B) percutaneous transluminal angioplasty resulting in flow limiting dissection and C) optimized by the implantation of two Multilink Vision stents (Abbott Vascular, Redwood City, CA, USA)

6-month binary restenosis rate of $39.1 \%$ using the BX Sonic (Cordis, Miami, FL, USA) stent, ${ }^{9}$ while Siablis et al. reported 12-month binary in-stent restenosis on angiography of $78.6 \%$ with a remarkable $100 \%$ limb salvage rate after having used a range of commercially available uncoated coronary BMS. ${ }^{10}$ Although satisfactory limb salvage rates are observed using coronary BMS in the lower leg, the long-term vessel patency seems to be too low to guarantee sustained interventional success (Figure 2).

Invatec was the first company to develop a dedicated infrapopliteal CoCr BMS; the Chromis Deep (Invatec, Roncadelle, Italy). The stent is available in longer lengths (up to $78 \mathrm{~mm}$ ), has a higher radial force than coronaryderived BMS and because of its closed cell design it offers homogeneous scaffolding of the vessel wall. Furthermore, the stent struts have low thickness, which provides better flexibility than coronary stent. Our group has performed BK stenting, using this device, in 50 patients with CLI and is currently awaiting the 6-month control data, which might show the value of this enhanced stent design (Figure 3).

\section{Passive coated balloon-expandable stents}

A first attempt to optimize the outcome of infrapopliteal stenting is application of passive stent coatings (carbon or silicon-carbide), which inhibit the deposition of thrombocytes and erythrocytes on the stent surface, preventing early thrombosis and intimal hyperplasia due to thrombus formation.

Peeters et al. presented our unpublished first infrapopliteal experience using the Silicon-Carbide coated Lekton (Biotronik AG, Bülach, Switzerland) at the TCT 2003 (Transcatheter Cardiovascular Therapeutics, Washington, USA). Our series of 50 consecutive patients treated with Lekton-stent implants in infrapopliteal lesions showed a 6-month primary patency rate of $91.1 \%$ on duplex and a limb salvage rate of $100 \%$.

More important was the RCT of the Vienna group: they were the first to prove that the angiographic outcome after stenting, using a stent with a passive coating, is superior to PTA alone in infrapopliteal vessels. Fiftyone patients presenting with CLI due to infrapopliteal lesions were randomized for treatment by PTA (53 lesions in 27 patients) or stent application (42 lesions in 24 patients). All patients in the stent arm received the coronary balloon-expandable carbon coated InPeria 

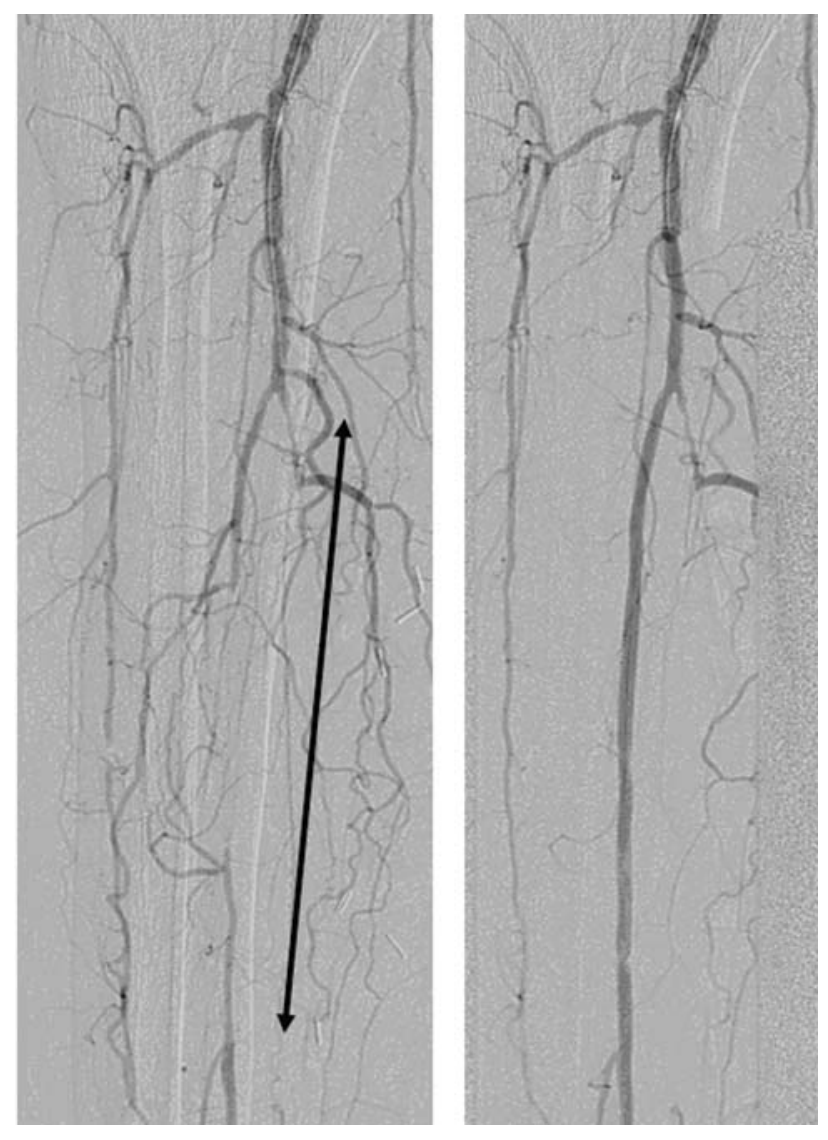

Figure 3 - A) Pre- and B) postoperative view of long occlusion of posterior tibial artery treated with a long dedicated infrapopliteal Chromis Deep stent (Invatec, Roncadelle, Italy)

Carbostent (Sorin, Biomedica, Italy). For the stent group the cumulative primary patency at 6 months was $83.7 \%$ at the $70 \%$ restenosis threshold, and $79.7 \%$ at the $50 \%$ restenosis threshold. For PTA, the primary patency at 6 months was $61.1 \%$ at the $70 \%$ restenosis threshold and $45.6 \%$ at the $50 \%$ restenosis threshold. Both results were statistically significant $(\mathrm{p}<0.05) .{ }^{11}$

\section{Drug eluting balloon-expandable stents}

In order to further improve infrapopliteal stent outcome, another coronary stent technique was transferred to the infrapopliteal vascular bed: the use of drugeluting stents (DES). An active stent coating (sirolimus or paclitaxel) inhibits the inflammatory response and smooth muscle cell proliferation in the vessel wall during a certain period, but in fact merely delays the process of intimal hyperplasia as demonstrated by the 2-year results of the SIROCCO study. ${ }^{12}$

Feiring et al. were the first to demonstrate the safety and utility of using coronary DES in the tibial vessels and paved the way for a more widespread application of DES for treating infrapopliteal disease. ${ }^{13}$

Based on the outcome of four independent investigator-initiated studies, the Cypher sirolimuseluting stent (SES) (Cordis, Miami, FL, USA), has been CE-marked for the BK indication. ${ }^{9,14-16}$ Our own study published in 2006 evaluating the Cypher stent for BK applications in 18 CLI patients (Rutherford 4 and 5) resulted in a 6-month limb salvage rate of $94.4 \%$ with an angiographic late lumen loss of only $0.38 \mathrm{~mm}$ in the surviving patients. ${ }^{15}$ Commeau et al. used SES to treat 30 consecutive patients with CLI (Rutherford category 3-6) and a minimum of two diseased infrapopliteal vessels. A limb salvage rate of $100 \%$ was achieved at a mean follow-up of 7.7 months, and all surviving patients treated with Cypher stents had marked clinical improvement with $97 \%$ primary patency as measured by target lesion revascularization (TLR). ${ }^{16}$ Siablis et al. compared the outcome of 29 CLI patients treated with the sirolimus-eluting Cypher stent with another 29 CLI patients receiving a BMS for infrapopliteal revascularization. The 6-month primary patency rate was significantly higher in the Cypher group compared to the BMS group (92.0 and $68.1 \%$ respectively, $\mathrm{p}<0.002$ ). Angiographic follow-up 6 months after index intervention revealed a binary in-stent restenosis of only $4.0 \%$ after Cypher stent implantation, while the rate was as high as $55.3 \%$ after BMS implantation $(\mathrm{p}<0.001) .{ }^{14}$ Siablis et al. also published their 1-year follow-up results showing $86.4 \%$ primary patency in patients with DES, whereas patients with BMS had primary patency of $40.5 \%$ ( $\mathrm{p}<$ 0.001). Likewise, the binary in-stent restenosis was better with DES, $36.7 \%$ in the Cypher stent group and $78.6 \%$ in the BMS group $(\mathrm{p}<0.001) .{ }^{10}$ The same highly significant difference in 6-month angiographic outcome between the Cypher and the non-drug-eluting BX Sonic stent (Cordis, Miami, FL, USA) was confirmed by Scheinert et al. in a non-randomized study. The study evaluated 60 consecutive patients presenting with 
infrapopliteal lesions. The binary restenosis rate was found to be $0 \%$ in the Cypher arm and $56.5 \%$ in the control BMS arm $(\mathrm{p}<0.001){ }^{9}$

Feiring et al. recently proposed a new technique for combining antegrade popliteal arterial access with tibial DES implantation in patients with SFA occlusions. Five patients scheduled for BK amputations successfully received overlapping infrapopliteal DES via this approach. After a mean follow-up period of 29 months, no deaths, no amputations and no TLR were recorded. ${ }^{17}$

To date, there is one publication on the use of paclitaxel-eluting stents (PES) in the given indication. Siablis et al. reported the 1-year angiographic and clinical outcomes of their prospective study investigating the infrapopliteal use of the Taxus PES (Boston Scientific Corp, Natick, MA, USA) in a group of 29 CLI patients (32 limbs, 50 lesions, 62 PES). At 1 year after index intervention, the limb salvage rate was $88.5 \%$. The published angiographic in-stent primary patency rate was only $30.0 \%$, with an in-stent binary $(>50 \%)$ restenosis of $77.4 \%$. The 1-year incidence of clinically-driven repeat interventions was $30.5 \%$. From their first experience with infrapopliteal PES, they concluded to have reached acceptable clinical results, even though PES implantation failed to inhibit vascular restenosis and to decrease the need for repeat interventions. ${ }^{18}$

Although evidence currently indicates that implantation of DES in the infrapopliteal vasculature leads to favorable outcomes with high mid-term primary patency and limb salvages rates, further support for the use of DES in patients with CLI and BK lesions will be gained from well-designed RCT. Such trials are about to start in conjunction with industry support. Another concern using DES in the infrapopliteal arteries is the delayed endothelialization around the stent struts as seen in coronaries, which makes the stent more susceptible to thrombosis. Despite the fact that DES thrombosis in the peripheral circulation has not the lethal consequences it has in coronary, dual antiplatelet therapy after DES is also warranted for PAOD to guarantee optimal stent performance and patient clinical well-being. Nevertheless, the use of dual antiplatelet therapy is associated with an increased incidence (1-2\% per year) of major bleeding complications and is expensive. ${ }^{19,20}$ The duration of

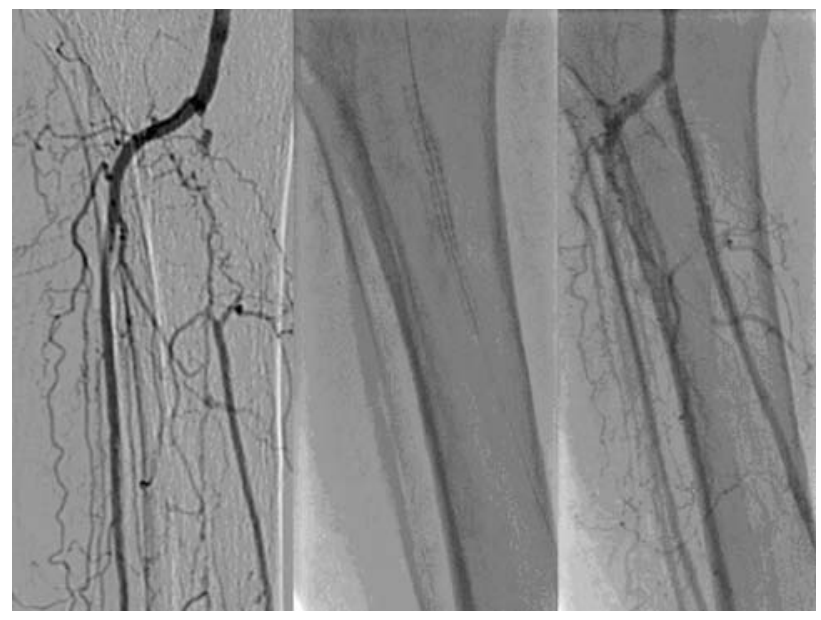

Figure 4 - A) Preoperative and B, C) postoperative angiographic control of stenting with a sirolimus-eluting Cypher stent (Cordis, Miami FL, USA) of a short focal infrapopliteal occlusion

treatment with dual antiplatelet therapy after both coronary and peripheral implantation of DES remains a subject of ongoing debate. Based on emerging evidence, many cardiologists are recommending a minimum of 12 months of aspirin and clopidogrel, but some are advocating indefinite use of dual antiplatelet therapy after DES implantation. ${ }^{21}$ One year of clopidogrel costs approximately US $\$ 1,000.00$. This expense is in addition to the cost already incurred by using a DES, which is usually fourfold greater than the bare metal equivalent; one coronary BMS costs US $\$ 800.00$ while one DES costs up to US\$ 2,500.00 22 (Figure 4).

\section{Nitinol self-expanding stents}

Despite those good outcomes in published trials, balloon-expandable stents are prone to fractures, as was recently documented by Schwarzmaier-D'Assie et al. ${ }^{23}$ Keeping in mind the findings in the superficial femoral artery, where Scheinert et al. found a direct link between stent fractures and lesion reocclusions, the fractureprone nature of balloon-expandable stainless steel could potentially lead to less encouraging long-term outcomes. ${ }^{24}$ Therefore it has been opted to develop selfexpanding nitinol stents for the infrapopliteal vessels. The potential advantage of nitinol could probably be explained by the crush-resistant, highly flexible nature 


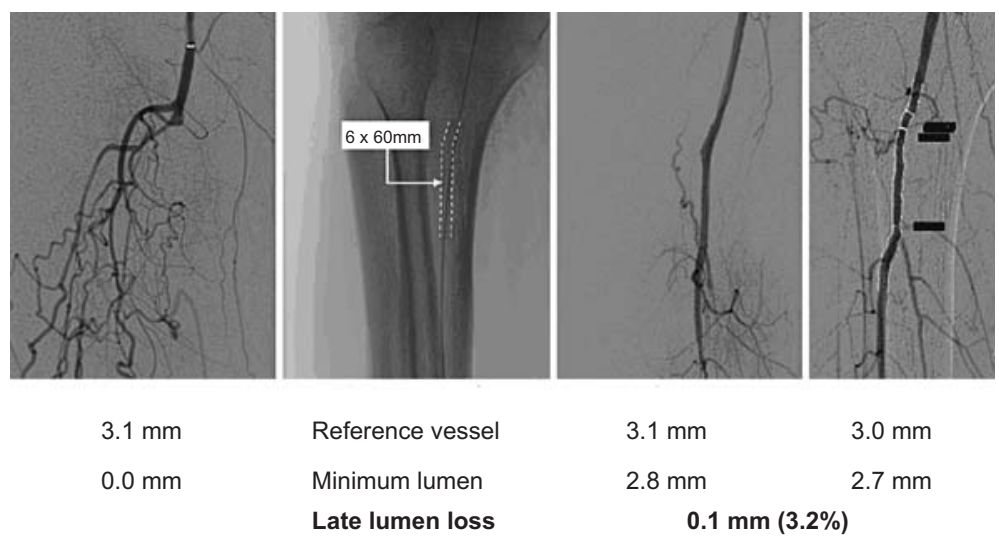

Figure 5 - Quantitative vessel analysis of patient treated with $6 \times 60$ Xpert nitinol stent (Abbott Vascular, Redwood City, CA, USA) for a total occlusion of the tibiofibular trunk (TFT). A) Preprocedural image showing total occlusion of the TFT; B) location of stent implantation; C) immediate postoperative image showing < $10 \%$ residual stenosis; D) 1-year angiographical control showed a late lumen loss (LLL) of only $0.1 \mathrm{~mm}$ (LLL-index 3.2\%)

of the alloy. Moreover, the design of dedicated smallvessel nitinol stents such as Xpert (Abbott Vascular, Redwood City, CA, USA), Astron Pulsar (Biotronik AG, Bülach, Switzerland) and Maris Deep (Invatec, Roncadelle, Italy) intends to improve results by a reduced strut profile, lowering the wall-coverage up to $20 \%$, independent of stent diameter. The rationale behind is that optimal maintenance of flow dynamics in the infrapopliteal arteries decreases lumen loss and improves patency rates.

Kickuth et al. were the first to present initial experience with the Xpert nitinol stent in the given indication with good clinical outcome after 6 months. ${ }^{25}$ Our group published the 1-year angiographic outcome of 47 CLI patients that received 67 Xpert stents for the treatment of 58 infrapopliteal lesions in 51 limbs. Angiographic control and subsequent quantitative vessel analysis (QVA) after 1 year showed a binary restenosis rate of $20.45 \%$. Kaplan Meier analysis reported 1-year primary patency and limb salvage rates of 76.3 and $95.9 \%$, respectively ${ }^{26}$ (Figure 5).

\section{Absorbable stents}

With all of presented stent types, the permanent presence of an artificial implant is believed to be the potential trigger for late restenosis. Recently, the stenting technology has moved towards the development of temporary implants composed of biocompatible materials which mechanically support the vessel during the period of high risk for recoil and then completely degrade on the long-term..$^{21,27-29}$ Therefore, bioabsorbable stents are regarded as a means of combining mechanical prevention of vessel recoil with various long-term advantages, when compared with permanent implants, including the possibility of late outward vessel remodeling and improved reintervention options. ${ }^{28}$ The bioabsorbable magnesium-alloy stent (AMS) (Biotronik AG, Bülach, Switzerland) was the first of its kind to be proved that it could be implanted safely in human arteries and that it was absorbed as intended. ${ }^{27,28}$ In the AMS BK study, clinical results using AMS stents for treatment of infrapopliteal lesions in 20 patients with CLI were presented. After 12 months, primary clinical patency and limb salvage rates were 73.3 and $94.7 \%$, respectively. ${ }^{30}$ Based on these findings, the AMS INSIGHT-1 RCT was set up to give further proof of the AMS safety and efficacy. The AMS INSIGHT-1 investigators have enrolled 117 CLI patients with BK 149 lesions. The patients were randomized to implantation of an AMS (60 patients, 74 lesions) or stand-alone PTA (57 patients, 75 lesions). Seven patients in the PTA group "crossed over" to AMS stenting. The primary safety endpoint was defined as 


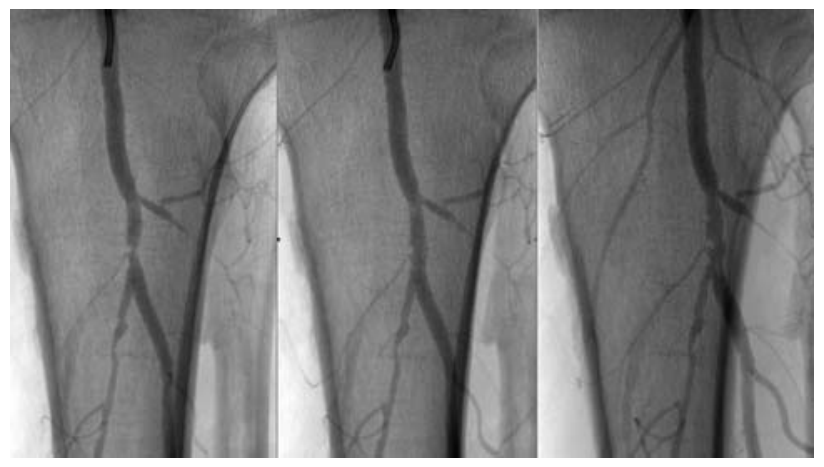

Figure 6 - Angiographic control of a A) $80 \%$ stenosis of the tibiofibular trunk, with B) 5\% residual stenosis after AMS (Biotronik AG, Bülach, Switzerland) implantation and C) 36\% in-stent restenosis at 6 months after index procedure

absence of major amputation and/or death within 30 days after index intervention and the primary efficacy endpoint was the 6-month angiographic patency rate as confirmed by core-lab quality assurance (QA). The 6-month clinical follow-up and efficacy data based on 6-month angiographic results for the AMS INSIGHT-1 study are expected to be published shortly (Figure 6).

\section{Conclusions}

Limb preservation should be the goal in patients with CLI due to tibial occlusive disease. With a prompt diagnosis, treatment can be started early and serious consequences may be avoided. Any type of revascularization that can prevent amputation must be applied to overall treatment strategy. ${ }^{31}$

To date, the PTA first strategy remains the standard of care, as it gives an acceptable clinical outcome at a low procedural cost. In case of suboptimal PTA, stent implantation with dedicated BK stents improves both the clinical outcome and decreases the need for TLR. For short focal lesions, current single center studies indicate that primary BK stenting can be a viable option in the infragenicular bed, but we will have to await future RCT comparing stenting vs. PTA in order to tell whether current or future stent improvements will change the idea about the optimal endovascular strategy.

Taking into account the findings of this literature review and the theory on the different stent designs, the authors believe that the future of infrapopliteal stents might lay in the development of small vessel sirolimuseluting, self-expanding nitinol stents or of sirolimuseluting absorbable stents.

\section{Acknowledgement}

The authors take great pleasure in thanking the staff of Flanders Medical Research Program (www.fmrp.be), with special regards to Koen De Meester for performing the systematic review of the literature and providing substantial support to the data analysis and the writing of the article.

\section{References}

1. Norgren L, Hiatt WR, Dormandy JA, et al. Inter-Society Consensus for the Management of Peripheral Arterial Disease (TASC II). J Vasc Surg. 2007; 45 Suppl S:S5-67.

2. Dorros G, Jaff MR, Dorros AM, Mathiak LM, He T. Tibioperoneal (outflow lesion) angioplasty can be used as primary treatment in 235 patients with critical limb ischemia: five-year follow-up. Circulation. 2001;104:2057-62.

3. Hanna GP, Fujise K, Kjellgren O, et al. Infrapopliteal transcatheter interventions for limb salvage in diabetic patients: importance of aggressive interventional approach and role of transcutaneous oximetry. J Am Coll Cardiol. 1997;30:664-9.

4. Parsons RE, Suggs WD, Lee JJ, Sanchez LA, Lyon RT, Veith FJ. Percutaneous transluminal angioplasty for the treatment of limb threatening ischemia: do the results justify an attempt before bypass grafting? J Vasc Surg. 1998;28:1066-71.

5. Ingle H, Nasim A, Bolia A, et al. Subintimal angioplasty of isolated infragenicular vessels in lower limb ischemia: long-term results. J Endovasc Ther. 2002;9:411-6.

6. Adam DJ, Beard JD, Cleveland T, et al. Bypass versus angioplasty in severe ischaemia of the leg (BASIL): multicentre, randomised controlled trial. Lancet. 2005;366:1925-34.

7. Goy JJ, Urban P. Life and limb: bypass versus angioplasty in the ischaemic limb. Lancet 2005;366:1905-6.

8. Bosiers M, Kallakuri S, Deloose K, Verbist J, Peeters P. Infragenicular angioplasty and stenting in the management of critical limb ischaemia: one year outcome following the use of the MULTI-LINK VISION stent. EuroIntervention. 2007;3:470-4.

9. Scheinert D, Ulrich M, Scheinert S, et al. Comparison of sirolimus-eluting vs. bare-metal stents for the treatment of infrapopliteal obstructions. EuroIntervention. 2006;2:169-74.

10. Siablis D, Karnabatidis D, Katsanos K, et al. Sirolimus-eluting versus bare stents after suboptimal infrapopliteal angioplasty for critical limb ischemia: enduring 1-year angiographic and clinical benefit. J Endovasc Ther. 2007;14:241-50.

11. Rand T, Basile A, Cejna M, et al. PTA versus carbofilm-coated stents in infrapopliteal arteries: pilot study. Cardiovasc Intervent Radiol. 2006;29:29-38. 
12. Duda S, Bosiers M, Lammer J, et al. Drug-eluting and bare nitinol stents for the treatment of atherosclerotic lesions in the superficial femoral artery: long-term results from the SIROCCO trial. J Endovasc Ther. 2006;13:701-10.

13. Feiring AJ, Wesolowski AA, Lade S. Primary stent-supported angioplasty for treatment of below-knee critical limb ischemia and severe claudication: early and one-year outcomes. Am Coll Cardiol. 2004:44:2307-14

14. Siablis D, Kraniotis P, Karnabatidis D, Kagadis GC, Katsanos K, Tsolakis J. Sirolimus-eluting versus bare stents for bailout after suboptimal infrapopliteal angioplasty for critical limb ischemia: 6-month angiographic results from a nonrandomized prospective single-center study. $\mathrm{J}$ Endovasc Ther. 2005;12:685-95.

15. Bosiers M, Deloose K, Verbist J, Peeters P. Percutaneous transluminal angioplasty for treatment of "below-the-knee" critical limb ischemia: early outcomes following the use of sirolimus-eluting stents. J Cardiovasc Surg (Torino). 2006;47:171-6.

16. Commeau P, Barragan P, Roquebert P. Sirolimus for below the knee lesions: mid-term results of SiroBTK study. Catheter Cardiovasc Interv. 2006;68:793-8.

17. Feiring AJ, Wesolowski AA. Antegrade popliteal artery approach for the treatment of critical limb ischemia in patients with occluded superficial femoral arteries. Catheter Cardiovasc Interv. 2007;69:665-70.

18. Siablis D, Karnabatidis D, Katsanos K, Diamantopoulos A, Christeas N, Kagadis GC. Infrapopliteal application of paclitaxel-eluting stents for critical limb ischemia: midterm angiographic and clinical results. J Vasc Interv Radiol. 2007;18:1351-61

19. Diener HC, Bogousslavsky J, Brass LM, et al. Aspirin and clopidogrel compared with clopidogrel alone after recent ischaemic stroke or transient ischaemic attack in high-risk patients (MATCH): randomised, double-blind, placebo-controlled trial. Lancet. 2004;364:331-7.

20. Eisenstein EL, Anstrom KJ, Kong DF, et al. Clopidogrel use and long-term clinical outcomes after drug-eluting stent implantation. JAMA. 2007;297:159-68.

21. Waksman R. Update on bioabsorbable stents: from bench to clinical. J Interv Cardiol. 2006;19:414-21.

22. Harper R. Drug-eluting stents coronary stents--a note of caution. Med J Aust. 2007;186:253-5.
23. Schwarzmaier-D'Assie A, Karnik R, Bonner G, Vavrik J, Slany $\mathrm{J}$. Fracture of a drug-eluting stent in the tibioperoneal trunk following bifurcation stenting. J Endovasc Ther. 2007;14:106-9.

24. Scheinert D, Scheinert S, Sax J, et al. Prevalence and clinical impact of stent fractures after femoropopliteal stenting. J Am Coll Cardiol. 2005;45:312-5.

25. Kickuth R, Keo H, Triller J, Ludwig K, Do DD. Initial clinical experience with the 4-F self-expanding XPERT stent system for infrapopliteal treatment of patients with severe claudication and critical limb ischemia. J Vasc Interv Radiol. 2007;18:703-8.

26. Romiti M, Albers M, Brochado-Neto FC, Durazzo AE, Pereira CA, De Luccia N. Meta-analysis of infrapopliteal angioplasty for chronic critical limb ischemia. J Vasc Surg. 2008;47:975-81.

27. Di Mario C, Griffiths H, Goktekin O, et al. Drug-eluting bioabsorbable magnesium stent. J Interv Cardiol. 2004;17:391-5.

28. Peeters P, Bosiers M, Verbist J, Deloose K, Heublein B. Preliminary results after application of absorbable metal stents in patients with critical limb ischemia. J Endovasc Ther. 2005;12:1-5.

29. Bosiers M, Deloose K, Verbist J, Peeters P. Will absorbable metal stent technology change our practice? J Cardiovasc Surg (Torino). 2006;47:393-7.

30. Bosiers M, Deloose K, Verbist J, Peeters P. First Clinical Application of Absorbable Metal Stents in the Treatment of Critical Limb Ischemia: 12-month results. Vasc Disease Management. 2005;2:86-91.

31. Allie D, Hebert C, Lirtzman M, et al. Critical Limb ischemia: a global epidemic. A Critical analysis of current treatment unmasks the clinical and economic costs of CLI. EuroIntervention 2005;1:75-84.

Correspondence:

Marc Bosiers

Department of Vascular Surgery

AZ St-Blasius

Kroonveldlaan 50

9200 Dendermonde, Belgium

Tel.: + 32 (0) 52252822

Fax: +32 (0) 52252289

E-mail: marc.bosiers@telenet.be 